\title{
Síndrome de duplicación 7q11.23. Primer caso descrito en América Latina
}

\author{
Chromosome 7q11.23 duplication syndrome. First reported case in Latin America
}

\author{
Dr. Felipe Ruiz Botero ${ }^{a}$, Dr. Wilmar Saldarriaga Gilb y Dra. Carolina Isaza de Lourido
}

\section{RESUMEN}

Elsíndrome de duplicación7q11.23es una patología causada por la duplicación de una región del cromosoma 7 que comprende 26 genes. El primer caso descrito en la literatura fue reportado por Somerville et al., en el año 2005, quienes describieron un paciente con dolicocefalia, frente alta y estrecha, pestañas largas, nariz alta y ancha, filtrum corto, paladar ojival, maloclusión dental, retrognatia y retardo grave en el lenguaje. Presentamos una paciente colombiana con hallazgo de duplicación 7q11.23 mediante técnicas de hibridación genómica comparativa y hallazgos clínicos clásicos. Este es el primer caso comunicado en Colombia y en América Latina.

Palabras clave: síndrome de duplicación del cromosoma 7q11.23, síndrome de duplicación de la región Williams-Beuren, síndrome de Williams, hibridación genómica comparativa, Colombia.

\begin{abstract}
7q11.23 duplication syndrome is a disease caused by duplication of a region of chromosome 7 comprising 26 genes. The first case described in the literature was reported by Somerville et al. in 2005, who described a patient with dolichocephaly, high and narrow forehead, long eyelashes, high and wide nose, short philtrum, high arched palate, dental malocclusion, retrognathia, and severe language delay. We report the case of a Colombian patient with 7q11.23 duplication by comparative genomic hybridization techniques, and classical clinical findings, this being the first reported case in Colombia and Latin America. Key words: chromosome 7q11.23 duplication syndrome, WilliamsBeuren region duplication syndrome, Williams syndrome, array comparative genomic hybridization, Colombia.
\end{abstract}

http:/ /dx.doi.org/10.5546/aap.2016.e1

a. Centro de Investigación en Anomalías Congénitas y Enfermedades Raras (CIACER) de la Facultad de Ciencias de la Salud de la Universidad Icesi.

b. Departamento de Morfología, Facultad de Salud, Universidad del Valle. Grupo de Malformaciones Congénitas (MACOS). Hospital Universitario del Valle. Cali, Colombia.

Correspondencia:

Dr. Felipe Ruiz Botero: Fruiz@icesi.edu.co

Financiamiento: Ninguno.

Conflicto de intereses: Ninguno que declarar.

Recibido: 17-4-2015

Aceptado: 27-8-2015

\section{INTRODUCCIÓN}

El síndrome de duplicación 7q11.23 (OMIM 609 757) es una patología causada por la duplicación de una región del cromosoma 7 que comprende 26 genes. La deleción de esta misma región cromosómica está asociada con el síndrome de Williams-Beuren. ${ }^{1}$ El primer caso descrito en la literatura fue reportado por Somerville et al. en el año 2005, quienes describieron un paciente con dolicocefalia, frente alta y estrecha, pestañas largas, nariz alta y ancha, filtrum corto, paladar ojival, maloclusión dental, retrognatia y retardo grave en el lenguaje. ${ }^{2}$ Posteriormente, otros autores reportaron pacientes con la misma deleción y que, además, presentaban labio superior delgado, asimetría facial, macrocefalia, hipotonía, retardo en el desarrollo psicomotor, grave compromiso del lenguaje, coeficiente intelectual promedio o déficit moderado. ${ }^{2-4} \mathrm{La}$ prevalencia para esta patología es desconocida y la mayoría de los casos descritos se deben a mutaciones de novo, pero, para los hijos de los afectados, la herencia se comporta como autosómica dominante. ${ }^{1,5}$

El objetivo de esta publicación es reportar sobre una paciente colombiana con hallazgo de duplicación 7q11.23 mediante técnicas de hibridación genómica comparativa y hallazgos clínicos clásicos. Este es el primer caso reportado en Colombia y en América Latina.

\section{PRESENTACIÓN DEL CASO}

Paciente de género femenino, producto de la cuarta gesta de padres no consanguíneos, de raza mestiza. Madre de 34 años (gesta 4, para 4) y padre de 51 años. Durante el control prenatal, no se reportaron hallazgos anormales en las ecografías tomadas en las semanas 14 y 24 de edad gestacional. Parto vaginal postérmino a las 43 semanas de edad gestacional, sin complicaciones durante el parto. A los 17 días de nacida, presentó síndrome convulsivo secundario a meningitis neonatal diagnosticada mediante punción lumbar, la cual fue tratada de manera satisfactoria. 
Durante su infancia, presentó retraso marcado del desarrollo psicomotor, con sostén cefálico a los 9 meses, bipedestación y marcha a los 3 años y desarrollo del habla a los 7 años de edad, con marcada dificultad para el aprendizaje. Además, presentó repetidas infecciones urinarias causadas por una vejiga hiperactiva, la cual se confirmó mediante estudios de urodinamia. La gammagrafía renal mostró una dilatación de los sistemas colectores en ambos riñones y un patrón no obstructivo con función renal del $51,8 \%$ en el riñón derecho y del $48 \%$ en el riñón izquierdo.

Actualmente, tiene 13 años de edad y asiste a la consulta de dismorfología y genética pediátrica del Hospital Universitario del Valle, en Cali (Colombia). En este hospital de III y IV nivel de referencia de la red pública del suroccidente colombiano, fue evaluada y se evidenció, al momento del examen físico, peso de $41 \mathrm{~kg}$ (p 25), talla de $146 \mathrm{~cm}$ (p 5-10), frente alta, enoftalmos, estrabismo convergente, filtrum corto, orejas cortas en copa bilateral, hipoplasia malar, signos de autoagresión en las extremidades superiores, hendidura en sandalia en los pies y ausencia de la menarca (Figuras 1 y 2). Se realizaron estudios paraclínicos complementarios, entre los cuales se incluyeron un test neuropsicológico, que reportó

FIGURA 1. Nótese frente alta, filtrum corto, hipoplasia malar

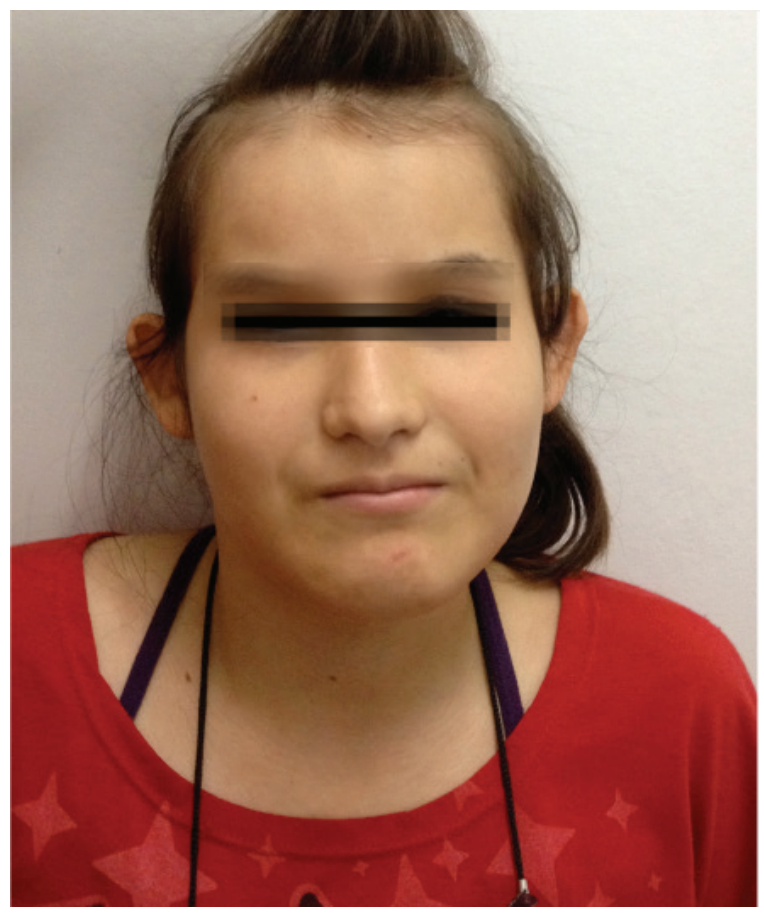

un coeficiente intelectual de 40 en la escala de Wechsler de inteligencia para niños, para una capacidad intelectual muy baja, y una resonancia magnética nuclear cerebral, que no reportó hallazgos anormales.

Inicialmente, se realizaron estudios de cariotipo bandeo $\mathrm{G}$ debido al dimorfismo facial de la paciente asociado a déficit cognitivo, pero el resultado de este no informó alteraciones citogénicas. Luego de esto, considerando adicionalmente los hallazgos de autoagresión en las extremidades superiores, se consideró que era necesario investigar síndromes que incluyeran en su espectro fenotípico el comportamiento autista, dentro de los cuales se encuentran como diagnósticos diferenciales: duplicaciones $15 q$, deleciones $16 p$, alteraciones locus $22 q 11$, síndrome de macrocefalia-autismo asociado al gen PTEN, síndrome de Rett, síndrome de Timothy, síndrome de Joubert, síndrome de Smith-Lemli-Opitz, síndrome de duplicación 7q11. Por esto, se decidió solicitar un estudio de hibridación genómica comparativa como parte del protocolo de estudio etiológico en pacientes con déficit cognitivo y espectro autista.

FIGURA 2. Nótese frente alta, filtrum corto, orejas cortas en copa bilateral

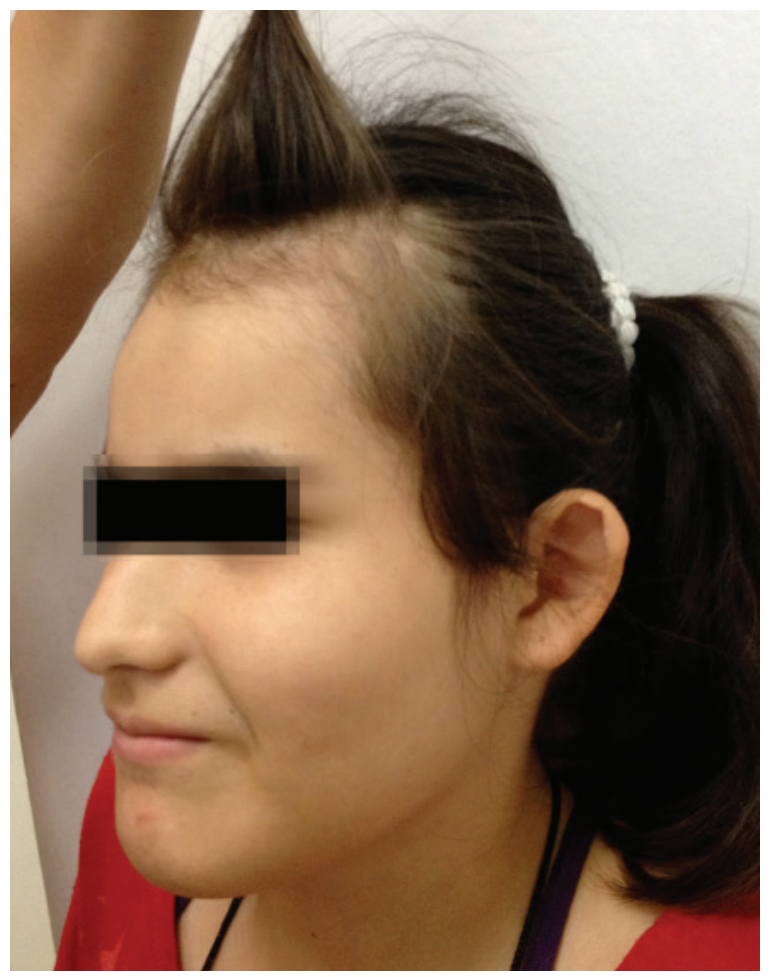


Se realizó hibridación genómica comparativa en array, que detectó arr 7q11.23(72,367,46573,771,409)x3, duplicación de aproximadamente 1,40 Mb que no solapó con variantes de copia numérica polimórficas y alteró la dosis de un micro ácido ribonucleico (ribonucleic acid; RNA, por sus siglas en inglés) y más de 30 genes. Esta variante solapó con una región de reordenamiento recurrente (flanqueada por duplicaciones segmentarias que favorecieron recombinaciones no homólogas de este segmento), congruente con el síndrome de microduplicación 7q11.23.

\section{DISCUSIÓN}

El síndrome de duplicación 7q11.23, también conocido como síndrome de duplicación de la región Williams-Beuren (OMIM 609 757), se caracteriza principalmente por la presencia de retardo en el desarrollo del lenguaje expresivo, en muchos casos, asociado a hallazgos compatibles con el espectro autista. ${ }^{6}$ Estas manifestaciones fenotípicas aluden a la posible presencia de genes sensibles a dosis asociados en el desarrollo del lenguaje dentro de esta región. ${ }^{6}$ Otros hallazgos típicos descritos incluyen anomalías menores craneofaciales, como frente prominente, cejas rectas, enoftalmos, nariz alta y ancha, labio superior delgado y filtrum corto. ${ }^{4,7}$ Estos hallazgos son compatibles con el fenotipo facial de la paciente actualmente reportada.

El síndrome de Williams-Beuren (OMIM 194050) se debe a una microdeleción en el segmento $7 \mathrm{q} 11.23$, y se reporta que afecta a 1 de cada 7500-20 000 nacidos vivos. ${ }^{2,8} \mathrm{La}$ microdeleción ocurre debido a una recombinación de alelos no homólogos entre copias de baja repetición que rodean la región deleteada. Dado que el mismo mecanismo explicaría una microduplicación, ${ }^{4}$ llama la atención que el síndrome de duplicación 7q11.23 no hubiese sido descrito antes, teniendo en cuenta que el diagnóstico podría realizarse con FISH utilizando la misma sonda que para el síndrome de Williams. También cabe resaltar que, en la actualidad, la prevalencia para esta patología es desconocida. Sin embargo, se ha estimado, sobre la base de la prevalencia del síndrome de Williams, que el síndrome de duplicación 7q11.23 ocurre en 1 de 7500 recién nacidos y en 1 por cada 12500 para las mutaciones de novo. ${ }^{1}$

Características fenotípicas opuestas han sido descritas en la literatura entre los pacientes con síndrome de Williams-Beuren y aquellos con síndrome de duplicación 7q11.23. Los pacientes con síndrome de Williams-Beuren presentan una nariz corta cóncava, filtrum largo, labios gruesos y facilidad para el lenguaje expresivo. A diferencia de cuando se presenta la microduplicación, se observan los hallazgos fenotípicos opuestos (previamente descritos), y es muy acentuado en el déficit para el desarrollo del lenguaje y en la interacción social. ${ }^{4,6,9}$ Sin embargo, en similitud a otros síndromes por microduplicaciones, el fenotipo expresado por los pacientes con duplicación de la región Williams-Beuren tiende a ser más suave con una expresividad muy variable, particularmente al compararlos con su correspondiente síndrome por microdeleción. Esto se considera que es la causa por la cual son escasos los reportes encontrados en la literatura y se cree que es el motivo de su subdiagnóstico.

La implementación de herramientas diagnósticas, como la hibridación genómica comparativa en array en el contexto de la pesquisa diagnóstica de pacientes con retardo del desarrollo del lenguaje, retardo mental, autismo y anomalías congénitas múltiples, ha facilitado el diagnóstico y la identificación de alteraciones genéticas clínicamente relevantes, como el síndrome de duplicación de la región Williams-Beuren. ${ }^{6,10}$ La inclusión de los estudios en array ha reemplazado los estudios de cariotipo de alta resolución como test inicial de evaluación de menores con autismo, y se han identificado alteraciones en $7 \%-20 \%$ de los casos previamente clasificados como de causa desconocida. ${ }^{11}$ En los casos de la pesquisa diagnóstica en los individuos con déficit cognitivo, su impacto ha sido contundente y ha pasado a ser considerado uno de los estudios que se deben realizar a principios de la evaluación diagnóstica y cuya utilidad es particularmente relevante en individuos en los que el análisis citogenético convencional ha sido negativo. ${ }^{12-14}$

En aquellos casos con retardo del desarrollo del lenguaje, retardo mental, autismo y/o hallazgos faciales, se debe tener en cuenta como un posible diagnóstico diferencial el síndrome de duplicación 7q11.23. También los autores sugieren a los especialistas en países latinoamericanos usar la hibridación genómica comparativa como una herramienta de utilidad dentro de la práctica clínica, particularmente en aquellos casos en los que se presentan alteraciones del desarrollo, ya sea mental, comportamental, psicomotor o del lenguaje, en asociación a hallazgos fenotípicos menores, en los que se puede lograr una mayor tasa diagnóstica, una mejor aproximación al 
pronóstico, encontrar tratamientos específicos y precisar asesoramiento genético. Se debe tener en cuenta la posibilidad de remitir muestras a laboratorios de referencia internacional en los países en que no se realiza la prueba.

\section{REFERENCIAS}

1. VellemanSL,Mervis CB. Children with7q11.23 duplication syndrome: speech, language, cognitive, and behavioral characteristics and their implications for intervention. Perspect Lang Learn Educ 2011;18(3):108-16.

2. Somerville MJ, Mervis CB, Young EJ, Seo EJ, et al. Severe expressive-language delay related to duplication of the Williams-Beuren locus. NEnglJMed 2005;353(16):1694-701.

3. Merla G, Brunetti-Pierri N, Micale L,Fusco C. Copy number variants at Williams-Beuren syndrome7q11.23 region. Hum Genet 2010;128(1):3-26.

4. Van der Aa N, Rooms L, Vandeweyer G, van den Ende J, et al. Fourteen new cases contribute to the characterization of the 7q11.23 microduplication syndrome. Eur JMed Genet 2009;52(2-3):94-100.

5. Berg JS, Brunetti-Pierri N, Peters SU, Kang SH, et al. Speech delay and autism spectrum behaviors are frequently associated with duplication of the 7q11.23 Williams-Beuren syndrome region. Genet Med 2007;9(7):427-41.

6. Dixit A, McKee S, Mansour S, Mehta SG, et al. 7q11.23
Microduplication: a recognizable phenotype. Clin Genet 2013;83(2):155-61.

7. Donnai D, Karmiloff-Smith A. Williams syndrome: from genotype through to the cognitive phenotype. Am J Med Genet 2000;97(2):164-71.

8. StrommeP, BjornstadPG, Ramstad K. Prevalenceestimation of Williams syndrome. J Child Neurol 2002;17(4):269-71.

9. Vargas C, Saldarriaga W, Pachajoa HM, Isaza C. Síndrome de Williams-Beuren: informe de dos casos con diagnóstico molecular. Colomb Med 2011;42(4):523-8.

10. Sanders SJ, Ercan-Sencicek AG,Hus V, Luo R, etal. Multiple recurrent de novo $\mathrm{CNVs}$, including duplications of the 7q11.23 Williams syndrome region, are strongly associated with autism. Neuron 2011;70(5):863-85.

11. Miles JH. Autism spectrum disorders-a genetics review. Genet Med 2011;13(4):278-94.

12. Mefford HC, Batshaw ML, Hoffman EP. Genomics, intellectual disability, and autism. $N$ Engl J Med 2012;366(8):733-43.

13. Sagoo GS, Butterworth AS, Sanderson S, Shaw-Smith C, et al. Array CGH in patients with learning disability (mental retardation) and congenital anomalies: updated systematic review and meta-analysis of 19 studies and 13,926 subjects . Genet Med 2009;11(3):139-46.

14. Bartnik M, Wi niowiecka-Kowalnik B, Nowakowska B, SmykM, etal. The usefulness of array comparative genomic hybridization in clinical diagnostics of intellectual disability in children. Dev Period Med 2014;18(3):307-17. 